\title{
Energy expenditure and physical activity in COPD by doubly labelled water method and an accelerometer
}

\author{
Hideaki Sato ${ }^{1}$, Hidetoshi Nakamura ${ }^{1}$, Yuki Nishida ${ }^{2}$, Toru Shirahata ${ }^{1}$, \\ Sanehiro Yogi ${ }^{1}$, Tomoe Akagami ${ }^{1}$, Machika Soma ${ }^{1}$, Kaiji Inoue ${ }^{3}$, Mamoru Niitsu $^{3}$, \\ Tomohiko Mio', Tatsuyuki Miyashita', Makoto Nagata', Satoshi Nakae ${ }^{2,4}$, \\ Yosuke Yamada ${ }^{2}$, Shigeho Tanaka ${ }^{2,5}$ and Fuminori Katsukawa ${ }^{6}$
}

Affiliations: ${ }^{1}$ Dept of Respiratory Medicine, Saitama Medical University, Saitama, Japan. ${ }^{2}$ National Institute of Health and Nutrition, National Institutes of Biomedical Innovation, Health and Nutrition, Tokyo, Japan. ${ }^{3}$ Dept of Radiology, Saitama Medical University, Saitama, Japan. ${ }^{4}$ Graduate School of Engineering Science, Osaka University, Osaka, Japan. ${ }^{5}$ Faculty of Nutrition, Kagawa Nutrition University, Saitama, Japan. ${ }^{6}$ Sports Medicine Research Center, Keio University, Kanagawa, Japan.

Correspondence: Hidetoshi Nakamura, Dept of Respiratory Medicine, Saitama Medical University, 38 Morohongo, Moroyama-machi, Iruma-gun, Saitama 350-0495, Japan. E-mail: hnakamurdsaitama-med.ac.jp

ABSTRACT Although weight loss suggests poor prognosis of COPD, only a few studies have examined total energy expenditure (TEE) or physical activity level (PAL) using the doubly labelled water (DLW) method. We evaluated TEE and PAL using the DLW method together with a triaxial accelerometer to elucidate the relationships between TEE, PAL and clinical parameters leading to a practical means of monitoring COPD physical status.

This study evaluated 50- to 79-year-old male patients with mild to very severe COPD $(n=28)$ or at risk for COPD $(n=8)$. TEE, activity energy expenditure for 2 weeks and basal metabolic rate were measured by DLW, an accelerometer and indirect calorimetry, respectively. All patients underwent pulmonary function, chest-computed tomography, 6-min walk test, body composition and grip strength tests. Relationships between indices of energy expenditure and clinical parameters were analysed. Bland-Altman analysis was used to examine the agreement of TEE and PAL between the DLW method and the accelerometer.

TEE and PAL using DLW in the total population were $2273 \pm 445 \mathrm{kcal}^{-d a y}{ }^{-1}$ and $1.80 \pm 0.20$, respectively. TEE by DLW correlated well with that from the accelerometer and grip strength $(\mathrm{p}<0.0001)$, and PAL by DLW correlated well with that from the accelerometer $(\mathrm{p}<0.0001)$, grip strength and 6 -min walk distance $(\mathrm{p}<0.001)$ among various clinical parameters. However, the accelerometer underestimated TEE $\left(215 \pm 241 \mathrm{kcal}^{\left.-\mathrm{day}^{-1}\right)}\right.$ and PAL $(0.18 \pm 0.16)$, with proportional biases in both indices.

TEE and PAL can be estimated by accelerometer in patients with COPD if systematic errors and relevant clinical factors such as muscle strength and exercise capacity are accounted for.

@ERSpublications

Although total energy expenditure and physical activity level in COPD patients were underestimated by an accelerometer, they can be predicted using indices of the accelerometer and clinical parameters such as the 6-min walk distance and grip strength. https://bit.ly/2OYbuaI

Cite this article as: Sato H, Nakamura H, Nishida Y, et al. Energy expenditure and physical activity in COPD by doubly labelled water method and an accelerometer. ERJ Open Res 2021; 7: 00407-2020 [https://doi.org/10.1183/23120541.00407-2020].

This article has supplementary material available from openres.ersjournals.com

Received: 20 June 2020 | Accepted: 16 March 2021

Copyright $\odot$ The authors 2021. This version is distributed under the terms of the Creative Commons Attribution NonCommercial Licence 4.0. For commercial reproduction rights and permissions contact permissions@ersnet.org 


\section{Introduction}

COPD is characterised by airflow limitation, with percentage forced expiratory volume in $1 \mathrm{~s}\left(\mathrm{FEV}_{1}\right)$ used as an index of the disease severity [1]. However, the introduction of the body mass index (BMI), airflow obstruction, dyspnoea, exercise capacity (BODE) index demonstrated that weight loss, dyspnoea and reduced exercise capacity should be considered simultaneously when trying to predict the COPD prognosis in addition to the obstructive disorder [2]. Furthermore, it has been reported that a low physical activity level (PAL) determined by a multisensory armband is the best predictor of poor COPD prognosis among all clinical parameters, which include percentage $\mathrm{FEV}_{1}, 6$-min walk distance (6 MWD), BMI, the modified Medical Research Council (mMRC) dyspnoea scale and the BODE index [3]. Recent investigations have highlighted the importance of providing adequate nutrition and exercise in order to maintain ideal body weight, muscle volume and strength, and physical activity, which can lead to improvement in the quality of life (QOL) and prognosis in COPD [4-7]. However, only a few studies have investigated total energy expenditure (TEE) in COPD using the standard doubly labelled water (DLW) method [8, 9]. Although prior studies that used the DLW method have suggested that patients with severe and very severe COPD tended to have an increased basal metabolic rate (BMR) and decreased activity energy expenditure (AEE) $[10,11]$, the characteristics of energy expenditure remain unclear in patients with mild to moderate COPD, who need to be prevented from developing physical inactivity and malnutrition. Although estimations of PAL using a pedometer or an accelerometer have shown a decrease in the PAL in accordance with the severity of airflow limitation $[12,13]$, it was reported that AEE determined by an accelerometer tended to underestimate values as compared to the DLW method [14], and that TEE calculated using the AEE and the predicted BMR was possibly underestimated in COPD patients.

Therefore, the present study attempted to accurately measure TEE and PAL in patients with mild to moderate COPD using the DLW method and indirect calorimetry in conjunction with an accelerometer, in order to elucidate the relationships between the TEE and PAL and clinical COPD parameters, which included pulmonary function, muscle volume and strength and exercise capacity. In addition, we tried to clarify the differences in the TEE and PAL assessments in COPD between the DLW method and the accelerometer, in order to evaluate the practical usefulness of the accelerometer.

\section{Methods}

\section{Study population}

This study enrolled patients with COPD $(n=28)$ and those at risk of COPD $(n=9)$. All patients were consecutive outpatients seen at the Saitama Medical University Hospital (Saitama, Japan) between June 2017 and February 2018, and who met the following criteria: male, age 50-79 years, presence of COPD (Global Initiative for Chronic Obstructive Lung Disease (GOLD) grade 1, 2, 3, 4) or at risk of COPD (GOLD 0). COPD was diagnosed in accordance with the GOLD 2020 guideline [1]. All GOLD 0 patients had chronic respiratory symptoms including cough, sputum or dyspnoea on exertion and a $\geqslant 10$-pack-year smoking history in the absence of airflow limitation $\left(\mathrm{FEV}_{1} /\right.$ forced vital capacity ratio $\left.\geqslant 0.7\right)$ after inhalation of bronchodilators. Exclusion criteria are described in the supplementary material. After one GOLD 0 patient discontinued the study due to acute bronchitis, a total of 36 patients were included in the analysis. This study was approved by the institutional review board of Saitama Medical University Hospital (no. 16-003-1), Keio University (protocol no. 2015-03) and National Institutes of Biomedical Innovation, Health and Nutrition (protocol no. 29). Written informed consent was obtained from each patient.

\section{Pulmonary function tests and 6-min walk test}

Pulmonary function tests were performed using a FUDAC-7 instrument (Fukuda Denshi, Tokyo, Japan). Spirometry parameters, lung volume subdivisions and the diffusing capacity of the lung for carbon monoxide $\left(D_{\mathrm{LCO}}\right)$ were measured in all patients. As indices of respiratory muscle strength, maximal expiratory and inspiratory pressure were measured using a spirometer (Autospiro AS-507; Minato Medical Science, Osaka, Japan). The predicted pulmonary function values were calculated according to the Japanese Respiratory Society guidelines [15]. The 6-min walk test (6MWT) was performed by experienced technicians in accordance with the American Thoracic Society guidelines, except for duplication [16]. The following data were collected in all patients: baseline oxygen saturation measured by pulse oximetry $\left(S_{\mathrm{pO}_{2}}\right)$ and heart rate (HR), lowest $S_{\mathrm{pO}_{2}}$ and highest HR during the test. Dyspnoea and leg fatigue were assessed using a modified Borg scale from 0 to 10 and the 6 -min walk distance (6MWD) was measured at the end of the test.

\section{Questionnaires and chest computed tomography analysis}

At the beginning of the study, severity of dyspnoea was estimated using the mMRC dyspnoea scale, while the disease-related QOL was evaluated using the COPD Assessment Test score. A chest computed tomography (CT) scanner (Somatom Emotion 16; Siemens Healthcare, Erlangen, Germany) and a Synapse 
Vincent volume analyser (Fujifilm Medical, Tokyo, Japan) were used for this study [17]. The conditions of the chest CT analysis are presented in the supplementary material.

\section{Study schedule}

This study was conducted in the hospital during two scheduled visits that occurred over 13-15 days. For both visits, patients arrived in a fasted state after overnight fasting. At visit 1, height, body weight and other baseline information was obtained. BMR was measured by indirect calorimetry while body composition was measured by bioelectrical impedance analysis. After taking DLW at visit 1, the physical activity was then measured using a triaxial accelerometer for 13-15 days. The 6MWT was performed within a month, while chest CT scans and pulmonary function tests were performed within 3 months before and after the study period. All of the examinations were performed under stable conditions.

Weight, body composition and grip strength

The methods for obtaining the weight, body composition and grip strength are shown in the supplementary material.

\section{Measurement of TEE by the DLW method}

TEE was measured by the DLW method (modified two-point approach) as reported previously [18]. At visit 1, an oral dose of $0.1 \mathrm{~g}^{2} \mathrm{H}_{2} \mathrm{O}$ and $2.0 \mathrm{~g} \mathrm{H}_{2}^{18} \mathrm{O}$ (Taiyo Nippon Sanso, Tokyo, Japan) per $\mathrm{kg}$ of estimated total body water was given to each patient. The specific details are described in the supplementary material.

\section{Measurement and prediction of BMR}

BMR was measured by indirect calorimetry $\left(\mathrm{BMR}_{\mathrm{I}}\right)$ at visit 1 (Quark RMR; COSMED, Rome, Italy) [19], while $\mathrm{BMR}_{\mathrm{G}}$ was predicted using the Ganpule equation [20, 21]. The detail is described in the supplementary material.

\section{Evaluation of PAL by the DLW method and an accelerometer}

PAL $_{\text {DLW }}$ was defined as follows:

$$
\mathrm{PAL}_{\mathrm{DLW}}=\mathrm{TEE}_{\mathrm{DLW}}(\mathrm{TEE} \text { by DLW method }) / \mathrm{BMR}_{\mathrm{I}}(\mathrm{BMR} \text { by indirect calorimetry })
$$

In addition, physical activity was evaluated using a triaxial accelerometer (Active Style Pro, HJA-750C; Omron Healthcare, Kyoto, Japan), which was developed to classify locomotive and nonlocomotive activities through the use of a ratio of unfiltered and filtered synthetic acceleration combined with a gravity-removal physical activity classification algorithm that was utilised for determining an accurate estimation of the AEE of nonlocomotive activities [22]. Metabolic equivalents (METs) were estimated by applying different equations for different types of activities. This analysis used the 60-s-epoch data. Periods with $>60$ min of consecutive nonwear time were classified as nonwear time, while a valid day was defined as $\geqslant 600$ min per day of wear time. Patients wore the accelerometer on their waist for 13-15 days, except during bathing and sleep. AEE is reasonably measured by the device, which also provides data regarding steps per day, sedentary ( $<1.5 \mathrm{METs})$ time and light $(1.5$ to $<3.0 \mathrm{METs})$, moderate $(3.0$ to $<6.0 \mathrm{METs})$ and vigorous $\left(\geqslant 6.0 \mathrm{METs}\right.$ ) walking and daily activity times. In this study, $\mathrm{PAL}_{\mathrm{ACC}}$ (PAL estimated by an accelerometer) was calculated as follows:

$$
\mathrm{TEE}_{\mathrm{ACC}}=\left(\mathrm{BMR}_{\mathrm{G}}+\mathrm{AEE}\right) \times 10 / 9, \quad \mathrm{PAL}_{\mathrm{ACC}}=\mathrm{TEE}_{\mathrm{ACC}} / \mathrm{BMR}_{\mathrm{G}}
$$

(10/9 was added to the equation for the correction of diet-induced thermogenesis (DIT)).

\section{Statistical analysis}

Data are presented as mean \pm SD. Values were compared between the DLW and the accelerometer using the paired t-test. Multiple comparisons were performed using the Tukey-Kramer test. Univariate associations were analysed using Pearson's correlation coefficient. Multiple regression analysis was performed to predict $\mathrm{TEE}_{\mathrm{DLW}}$ and PAL $\mathrm{PLW}$. The Bland-Altman plot was used to evaluate the agreement of TEE and PAL between DLW and accelerometer methods, and of BMR between indirect calorimetry and the Ganpule equation. p-values $<0.05$ were considered significant. All data were analysed using JMP version 14 software (SAS Institute, Cary, NC, USA). 


\section{Results}

Characteristics of the patients

As shown in table 1 , the total population primarily consisted of patients with mild to moderate COPD (20 out of 36), with a mean $\mathrm{FEV}_{1}$ of $69.4 \%$ predicted.

Energy expenditure and physical activity in accordance with the severity of airflow limitation BMI was lower in GOLD grades 3 and 4 versus GOLD 2 (table 2). There were no differences in TEE $\mathrm{DLW}_{\text {, }}$ $\mathrm{PAL}_{\mathrm{DLW}}$ and $\mathrm{BMR}_{\mathrm{I}}$ among patients at risk of COPD or with mild to very severe COPD. For the accelerometer, there was no difference in any of the parameters except for a decrease in the moderate walking time in GOLD grades 3 and 4 versus GOLD grade 1.

There were significant differences in the TEE between GOLD 1 and 2 observed for the DLW and the accelerometer (figure 1a). For PAL, there were significant differences observed for all comparisons between the DLW and the accelerometer (figure 1b).

Validation of $T E E_{A C C}$ and $P A L_{A C C}$ in comparison with $T E E_{D L W}$ and $P A L_{D L W}$, and of $B M R_{G}$ to $B M R_{l}$ using Bland-Altman plots

As shown in figure 2, fixed bias was observed in both the TEE (95\% CI 133.5-296.6 kcal-day $\left.{ }^{-1}, \mathrm{p}<0.0001\right)$ and PAL (95\% CI 0.129-0.235, p<0.0001) between the two methods. Proportional bias was also observed in both TEE $(r=0.561, p=0.0004)$ and PAL $(r=0.482, p=0.0029)$. No fixed bias was seen in BMR $(95 \% \mathrm{CI}$ $-25.8-4.1 \mathrm{kcal}^{-\mathrm{day}^{-1}}{ }^{-}$, nonsignificant), whereas slight proportional bias was observed $(\mathrm{r}=0.399, \mathrm{p}=0.016)$.

When $\mathrm{TEE}_{\mathrm{ACC}}$ and $\mathrm{PAL}_{\mathrm{ACC}}$ were calculated with $\mathrm{BMR}_{\mathrm{I}}$ instead of $\mathrm{BMR}_{\mathrm{G}}$, the fixed and proportional

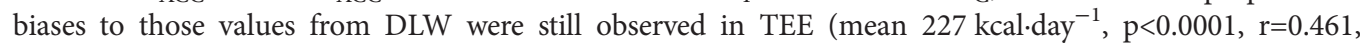
$\mathrm{p}=0.0046$ ) and PAL (mean 0.176, $\mathrm{p}<0.0001, \mathrm{r}=0.451, \mathrm{p}=0.0058$ ), respectively, by Bland-Altman analyses.

Using $\mathrm{AEE}_{\mathrm{DLW}}$ (defined as $0.9 \times \mathrm{TEE}_{\mathrm{DLW}}-\mathrm{BMR}_{\mathrm{I}}$ ), the difference between $\mathrm{TEE}_{\mathrm{DLW}}$ and $\mathrm{TEE}_{\mathrm{ACC}}$ correlated well with $\operatorname{AEE}_{\mathrm{DLW}}(\mathrm{r}=0.732, \mathrm{p}<0.0001)$ and modestly with $\mathrm{BMR}_{\mathrm{I}}(\mathrm{r}=0.488, \mathrm{p}=0.0025)$. The difference

\section{TABLE 1 Patient characteristics}

\begin{tabular}{|c|c|c|c|c|}
\hline & All & GOLD 0 & COPD (GOLD 1-4) & GOLD 0 versus COPD \\
\hline Subjects & 36 & 8 & $28(1 \mathrm{n}=6,2 \mathrm{n}=14,3 \mathrm{n}=6,4 \mathrm{n}=2)$ & \\
\hline Age years & $70.3 \pm 5.8$ & $70.3 \pm 7.1$ & $70.3 \pm 5.5$ & NS \\
\hline mMRC & $0.9 \pm 1.0$ & $0.4 \pm 0.5$ & $1.1 \pm 1.0$ & NS \\
\hline CAT score & $10.1 \pm 6.1$ & $9.6 \pm 4.0$ & $10.2 \pm 6.7$ & NS \\
\hline BMI $\mathrm{kg} \cdot \mathrm{m}^{-2}$ & $21.9 \pm 3.2$ & $21.2 \pm 3.7$ & $22.1 \pm 3.2$ & NS \\
\hline Fat mass $\%$ & $23.3 \pm 5.0$ & $24.6 \pm 3.4$ & $22.9 \pm 5.3$ & NS \\
\hline FFMI $\mathrm{kg} \cdot \mathrm{m}^{-2}$ & $16.7 \pm 2.3$ & $15.9 \pm 2.7$ & $16.9 \pm 2.2$ & NS \\
\hline $\mathrm{SMI} \mathbf{k g} \cdot \mathrm{m}^{-2}$ & $9.1 \pm 1.0$ & $8.8 \pm 1.2$ & $9.2 \pm 0.9$ & NS \\
\hline Grip strength kg & $33.9 \pm 7.0$ & $29.6 \pm 6.1$ & $35.1 \pm 6.8$ & $p<0.05$ \\
\hline$P_{\text {Emax }} \%$ & $72.6 \pm 18.7$ & $71.8 \pm 22.1$ & $72.8 \pm 18.0$ & NS \\
\hline$P_{\operatorname{Imax}} \%$ & $87.6 \pm 29.3$ & $89.8 \pm 15.7$ & $87.0 \pm 32.3$ & NS \\
\hline Vital capacity $\%$ & $95.3 \pm 16.2$ & $98.9 \pm 12.0$ & $94.2 \pm 17.2$ & NS \\
\hline FEV $_{1} \%$ pred & $69.4 \pm 24.4$ & $94.6 \pm 10.7$ & $62.1 \pm 22.3$ & $p<0.001$ \\
\hline FEV $_{1} /$ FVC $\%$ & $55.4 \pm 17.4$ & $78.5 \pm 7.8$ & $48.8 \pm 13.2$ & $p<0.0001$ \\
\hline Residual volume \% & $117.1 \pm 35.4$ & $99.4 \pm 17.2$ & $122.2 \pm 37.7$ & NS \\
\hline$D_{\mathrm{Lco}} / V_{\mathrm{A}} \%$ & $74.0 \pm 27.4$ & $83.1 \pm 19.4$ & $71.5 \pm 29.0$ & NS \\
\hline LAA $\%$ & $13.9 \pm 13.6$ & $9.4 \pm 8.6$ & $15.1 \pm 14.6$ & NS \\
\hline 6MWD m & $435 \pm 95$ & $442 \pm 23$ & $433 \pm 107$ & NS \\
\hline$\Delta S_{\mathrm{pO}_{2}} \%$ & $7.3 \pm 4.6$ & $4.4 \pm 2.4$ & $8.1 \pm 4.7$ & $p<0.05$ \\
\hline$\Delta \mathrm{HR}$ beats $\cdot \mathrm{min}^{-1}$ & $38.2 \pm 15.2$ & $31.5 \pm 7.2$ & $40.1 \pm 16.4$ & NS \\
\hline Dyspnoea & $2.2 \pm 2.2$ & $1.1 \pm 1.4$ & $2.5 \pm 2.4$ & NS \\
\hline Leg fatigue & $0.7 \pm 1.3$ & $0.8 \pm 1.2$ & $0.7 \pm 1.3$ & NS \\
\hline
\end{tabular}

Data are presented as $n$ or mean $\pm S D$, unless otherwise stated. GOLD: Global Initiative for Chronic Obstructive Lung Disease; mMRC: modified Medical Research Council dyspnoea scale; CAT: COPD Assessment Test; BMI: body mass index; FFMI: fat-free mass index; SMI: skeletal muscle mass index; $P_{\text {Emax }}$ : maximum expiratory pressure; $P_{\text {Imax }}$ : maximum inspiratory pressure; $\mathrm{FEV}_{1}$ : forced expiratory volume in $1 \mathrm{~s}$; FVC: forced vital capacity; $D_{\mathrm{Lco}}$ : diffusing capacity of the lung for carbon monoxide; $V_{\mathrm{A}}$ : alveolar volume; LAA: low attenuation area; 6MWD: 6-min walk distance; $S_{\mathrm{pO}_{2}}$ : percutaneous oxygen saturation; $\triangle \mathrm{HR}$ : difference in heart rate; NS: nonsignificant. 


\begin{tabular}{|c|c|c|c|c|c|c|c|}
\hline & All (GOLD 0-4) & GOLD 0 & GOLD 1 & GOLD 2 & GOLD 3,4 & COPD (GOLD 1-4) & Multiple comparison \\
\hline Subjects & 36 & 8 & 6 & 14 & 8 & 28 & \\
\hline Age years & $70.3 \pm 5.8$ & $70.3 \pm 7.1$ & $68.8 \pm 8.9$ & $71.4 \pm 4.4$ & $69.6 \pm 4.5$ & $70.3 \pm 5.5$ & NS \\
\hline BMI $\mathrm{kg} \cdot \mathrm{m}^{-2}$ & $21.9 \pm 3.2$ & $21.2 \pm 3.7$ & $21.8 \pm 1.3$ & $23.5 \pm 3.0$ & $19.7 \pm 3.2^{\#}$ & $22.1 \pm 3.2$ & $p<0.05^{\#}$ \\
\hline $\mathrm{BMR}_{\mathrm{I}}$ kcal-day ${ }^{-1}$ & $1262 \pm 180$ & $1229 \pm 234$ & $1297 \pm 173$ & $1316 \pm 158$ & $1172 \pm 148$ & $1271 \pm 165$ & NS \\
\hline BMR $_{G}$ kcal-day ${ }^{-1}$ & $1272 \pm 145$ & $1254 \pm 201$ & $1278 \pm 124$ & $1309 \pm 133$ & $1223 \pm 125$ & $1278 \pm 129$ & NS \\
\hline $\mathrm{BMR}_{\mathrm{l}} / \mathrm{BMR}_{\mathrm{G}}$ & $0.99 \pm 0.07$ & $0.98 \pm 0.08$ & $1.01 \pm 0.06$ & $1.01 \pm 0.07$ & $0.96 \pm 0.07$ & $0.99 \pm 0.07$ & NS \\
\hline TEE $_{\text {DLw }}$ kcal-day ${ }^{-1}$ & $2273 \pm 445$ & $2240 \pm 629$ & $2496 \pm 435$ & $2378 \pm 322$ & $1956 \pm 296$ & $2283 \pm 393$ & NS \\
\hline TEE $_{\text {ACc }}$ kcal-day ${ }^{-1}$ & $2058 \pm 315$ & $1982 \pm 353$ & $2168 \pm 292$ & $2146 \pm 308$ & $1897 \pm 269$ & $2080 \pm 307$ & NS \\
\hline 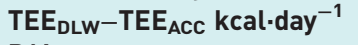 & $215 \pm 241$ & $258 \pm 324$ & $327 \pm 299$ & $232 \pm 188$ & $59 \pm 120$ & $203 \pm 218$ & NS \\
\hline PAL DLW & $1.80 \pm 0.20$ & $1.80 \pm 0.22$ & $1.92 \pm 0.16$ & $1.81 \pm 0.19$ & $1.67 \pm 0.21$ & $1.80 \pm 0.20$ & NS \\
\hline $\mathrm{PAL}_{\mathrm{ACC}}$ & $1.61 \pm 0.14$ & $1.58 \pm 0.12$ & $1.70 \pm 0.13$ & $1.64 \pm 0.13$ & $1.55 \pm 0.14$ & $1.63 \pm 0.14$ & NS \\
\hline $\mathrm{PAL}_{\mathrm{DLW}}-\mathrm{PAL}_{\mathrm{ACC}}$ & $0.18 \pm 0.16$ & $0.22 \pm 0.16$ & $0.22 \pm 0.16$ & $0.18 \pm 0.18$ & $0.12 \pm 0.09$ & $0.17 \pm 0.16$ & NS \\
\hline $\mathrm{AEE}_{\mathrm{ACC}}{\mathrm{kcal} \cdot \mathrm{day}^{-1}}^{-1}$ & $580 \pm 178$ & $529 \pm 156$ & $674 \pm 180$ & $623 \pm 181$ & $484 \pm 162$ & $594 \pm 184$ & NS \\
\hline Steps per day & $5978 \pm 3209$ & $5808 \pm 3171$ & $7778 \pm 3590$ & $5874 \pm 2116$ & $5079 \pm 4482$ & $6055 \pm 3273$ & NS \\
\hline Sedentary min & $506 \pm 137$ & $456 \pm 112$ & $456 \pm 112$ & $472 \pm 155$ & $580 \pm 125$ & $499 \pm 144$ & NS \\
\hline Light walking min & $38.8 \pm 27.6$ & $30.0 \pm 18.5$ & $40.3 \pm 22.5$ & $35.7 \pm 20.8$ & $51.9 \pm 44.6$ & $41.3 \pm 29.5$ & NS \\
\hline Moderate walking min & $28.4 \pm 23.5$ & $30.6 \pm 21.4$ & $44.5 \pm 29.1$ & $30.3 \pm 22.0$ & $10.6 \pm 14.1 *$ & $27.7 \pm 24.3$ & $p<0.05^{*}$ \\
\hline Vigorous walking min & $0.08 \pm 0.28$ & $0.13 \pm 0.35$ & $0.17 \pm 0.41$ & $0.07 \pm 0.27$ & 0 & $0.07 \pm 0.26$ & NS \\
\hline Light daily activity min & $261 \pm 83$ & $243 \pm 84$ & $301 \pm 83$ & $267 \pm 80$ & $237 \pm 87$ & $266 \pm 83$ & NS \\
\hline Moderate daily activity min & $19.9 \pm 17.9$ & $16.9 \pm 14.6$ & $25.5 \pm 14.2$ & $25.6 \pm 22.4$ & $8.8 \pm 7.9$ & $20.8 \pm 18.8$ & NS \\
\hline \multicolumn{8}{|c|}{$\begin{array}{l}\text { Data are presented as } n \text { or mean } \pm \text { SD, unless otherwise stated. GOLD: Global Initiative for Chronic Obstructive Lung Disease; BMI: body mass } \\
\text { index; BMR: basal metabolic rate; BMR, BMR measured by indirect calorimetry; BMR } \text { B }_{\text {B }} \text { BMR predicted using the Ganpule equation; TEE: total } \\
\text { energy expenditure; DLW: doubly labelled water; ACC: accelerometer; PAL: physical activity level; AEE: activity energy expenditure; } \\
\text { NS: nonsignificant. *: } p<0.05 \text { versus GOLD } 1 ;{ }^{\#}: p<0.05 \text { versus GOLD } 2 \text {. }\end{array}$} \\
\hline
\end{tabular}

between $\mathrm{PAL}_{\mathrm{DLW}}$ and $\mathrm{PAL}_{\mathrm{ACC}}$ correlated well with $\mathrm{AEE}_{\mathrm{DLW}}(\mathrm{r}=0.680, \mathrm{p}<0.0001)$, but not with $\mathrm{BMR}_{\mathrm{I}}$. A significant difference was apparent between $\mathrm{AEE}_{\mathrm{DLW}}\left(784 \pm 275 \mathrm{kcal} \cdot \mathrm{day}^{-1}\right)$ and $\mathrm{AEE}_{\mathrm{ACC}}$ $\left(580 \pm 178 \mathrm{kcal} \cdot \mathrm{day}^{-1}, \mathrm{p}<0.0001\right)$.

\section{Univariate regression analysis between energy expenditure, physical activity and clinical parameters}

Various factors including age, BMI, fat-free mass index (FFMI), skeletal muscle mass index (SMI), grip strength, percentage vital capacity $(\% \mathrm{VC}), \% D_{\mathrm{LCO}} /$ alveolar volume $\left(V_{\mathrm{A}}\right)$, low attenuation area $(\mathrm{LAA}) \%$, $6 \mathrm{MWD}$, change in $\mathrm{HR}$ and leg fatigue during the $6 \mathrm{MWT}$ were associated with $\mathrm{TEE}_{\mathrm{DLW}}$ (table 3 ). In contrast, the factors related to $\mathrm{PAL}_{\mathrm{DLW}}$ were limited to $6 \mathrm{MWD}$, change in $\mathrm{HR}$ during $6 \mathrm{MWT}$, grip strength and $\% \mathrm{FEV}_{1}$. Figure 3 shows the association of the cardinal clinical parameters with $\mathrm{TEE}_{\mathrm{DLW}}$ (figure $3 \mathrm{a}$ ) and $\mathrm{PAL}_{\mathrm{DLW}}$ (figure $3 \mathrm{~b}$ ).

\section{Relationships between energy expenditure, physical activity and the parameters of the} accelerometer

As shown in table 4, light and moderate daily activity times were correlated with both indices. Furthermore, there was a good correlation between $\mathrm{TEE}_{\mathrm{DLW}}$ and $\mathrm{TEE}_{\mathrm{ACC}}$. These associations are shown in figure $4 \mathrm{a}\left(\mathrm{TEE}_{\mathrm{DLW}}\right)$ and $4 \mathrm{~b}\left(\mathrm{PAL}_{\mathrm{DLW}}\right)$.

\section{Prediction of TEE $D L W$ and $P A L_{D L W}$ according to the accelerometer and clinical parameters}

Since $\mathrm{TEE}_{\mathrm{DLW}}$ correlated strongly with $\mathrm{TEE}_{\mathrm{ACC}}$, the following equation may predict $\mathrm{TEE}_{\mathrm{DLW}}$ using the accelerometer: $\mathrm{TEE}_{\mathrm{DLW}}=-210.2+1.207 \times \mathrm{TEE}_{\mathrm{ACC}}(\mathrm{r}=0.854$, corrected coefficient of determination=0.721). When this equation was used to predict $\mathrm{TEE}_{\mathrm{DLW}}$ based on $\mathrm{TEE}_{\mathrm{ACC}}$ values in all 36 patients, the ratio of patients for whom predicted values were within $\pm 10 \%$ of measured $\mathrm{TEE}_{\mathrm{DLW}}$ was $58 \%$. In contrast, $\mathrm{PAL}_{\mathrm{DLW}}$ correlated modestly with $\mathrm{PAL}_{\mathrm{ACC}}(\mathrm{r}=0.642$, corrected coefficient of determination=0.395). Multiple regression analyses including clinical parameters are shown in the supplementary material.

\section{Discussion}

The present study demonstrated that BMR, TEE and PAL as evaluated by indirect calorimetry and DLW methods were preserved as nearly normal among patients at risk for or with mild to moderate COPD. These three indices tended to decrease in patients with severe to very severe COPD. YAMADA et al. [23] 
a)
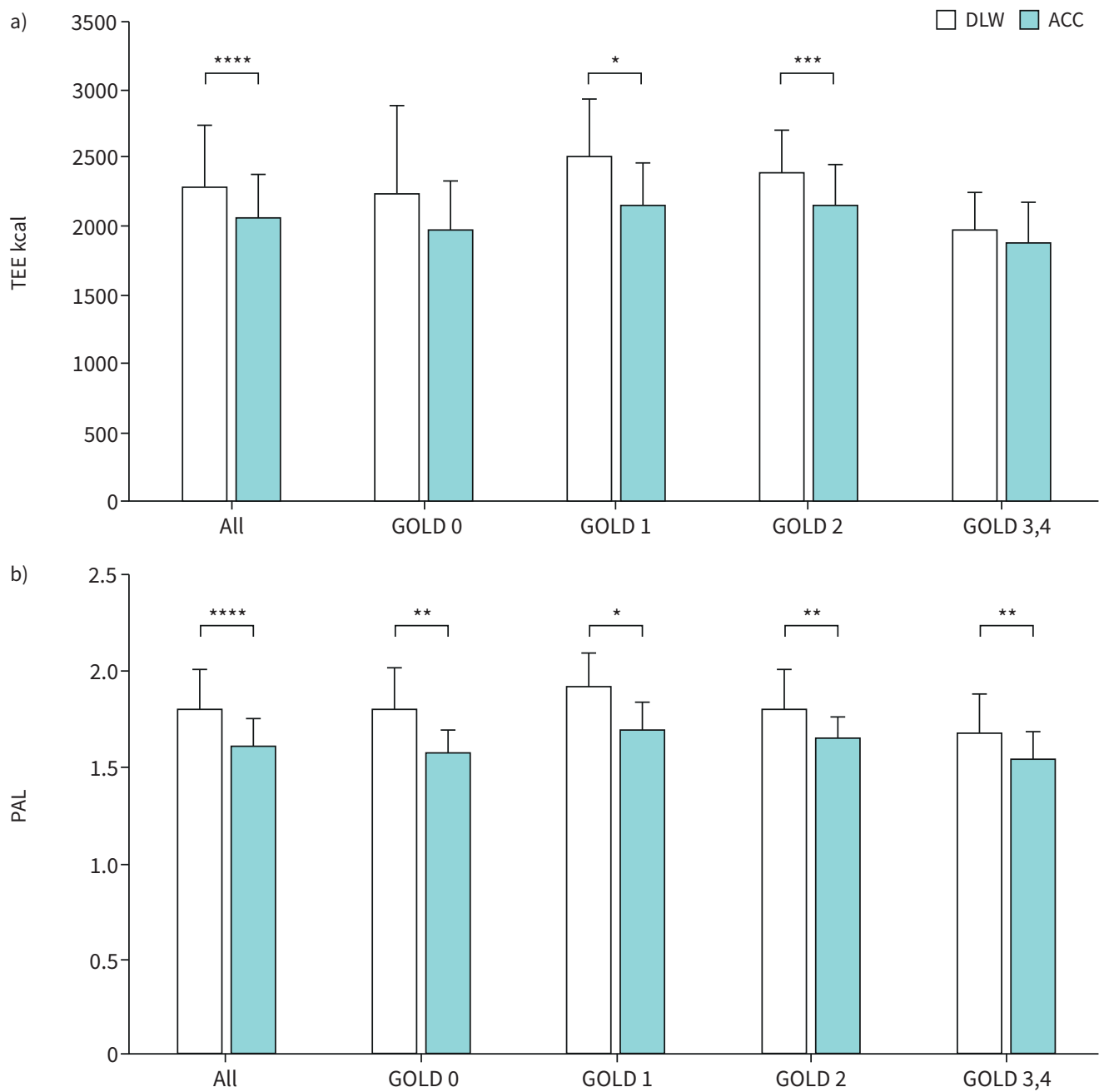

FIGURE 1 Differences in a) total energy expenditure (TEE) and b) physical activity level (PAL) between the doubly labelled water (DLW) method and measurement by accelerometer (ACC). Significant differences in TEE (all, Global Initiative for Chronic Obstructive Lung Disease (GOLD) 1 and GOLD 2) and PAL lall, GOLD 0 , GOLD 1, GOLD 2 and GOLD 3,4) were observed between the two methods. ${ }^{*}: p<0.05,{ }^{* *}: p<0.01,{ }^{* * *}$ : $p<0.001$, $* * * *: p<0.0001$

reported that elderly men in the Japanese community without any associated participation in sporting activities showed a mean BMI $23.6 \mathrm{~kg} \cdot \mathrm{m}^{-2}, \mathrm{BMR}_{\mathrm{I}} 1242 \mathrm{kcal} \cdot \mathrm{day}^{-1}, \mathrm{TEE}_{\mathrm{DLW}} 2308 \mathrm{kcal} \cdot \mathrm{day}^{-1}$ and $\mathrm{PAL}_{\mathrm{DLW}}$ 1.85 , similar to that found for COPD patients at GOLD 1 and 2 in this study. No significant difference in BMR was seen between measured values and prediction by the Ganpule equation even in COPD patients, although slight proportional bias was observed by Bland-Altman plots in the present study. The DLW method is the gold standard for measuring TEE [24]. However, since this method is difficult to apply during routine clinical practice, comparison of data from the DLW method and indirect calorimetry with that for the accelerometer and predicted BMR is important. The present study demonstrated that TEE and PAL by the DLW method correlated well with those from the accelerometer, but were underestimated by the accelerometer (fixed bias), as reported previously [14, 23]. In addition, in conjunction with the increases in TEE and PAL, the differences in TEE and PAL between the two methods also increased (proportional bias), respectively.

As stated in the results section, differences in TEE and PAL paralleled the AEE as evaluated by the DLW method. Since TEE and PAL are composed of BMR, AEE and DIT, these three factors should be tested as causes for biases between DLW and accelerometer-based methods. Bland-Altman analyses using measured BMR values did not significantly improve the biases, and a prior study did not show significant changes in DIT in patients with COPD [25]. Thus, underestimation of AEE by the accelerometer may be mainly responsible for the fixed and proportional biases between the two methods. One possibility is that energy expenditure by respiratory muscles that was not detected by the accelerometer could have been further 

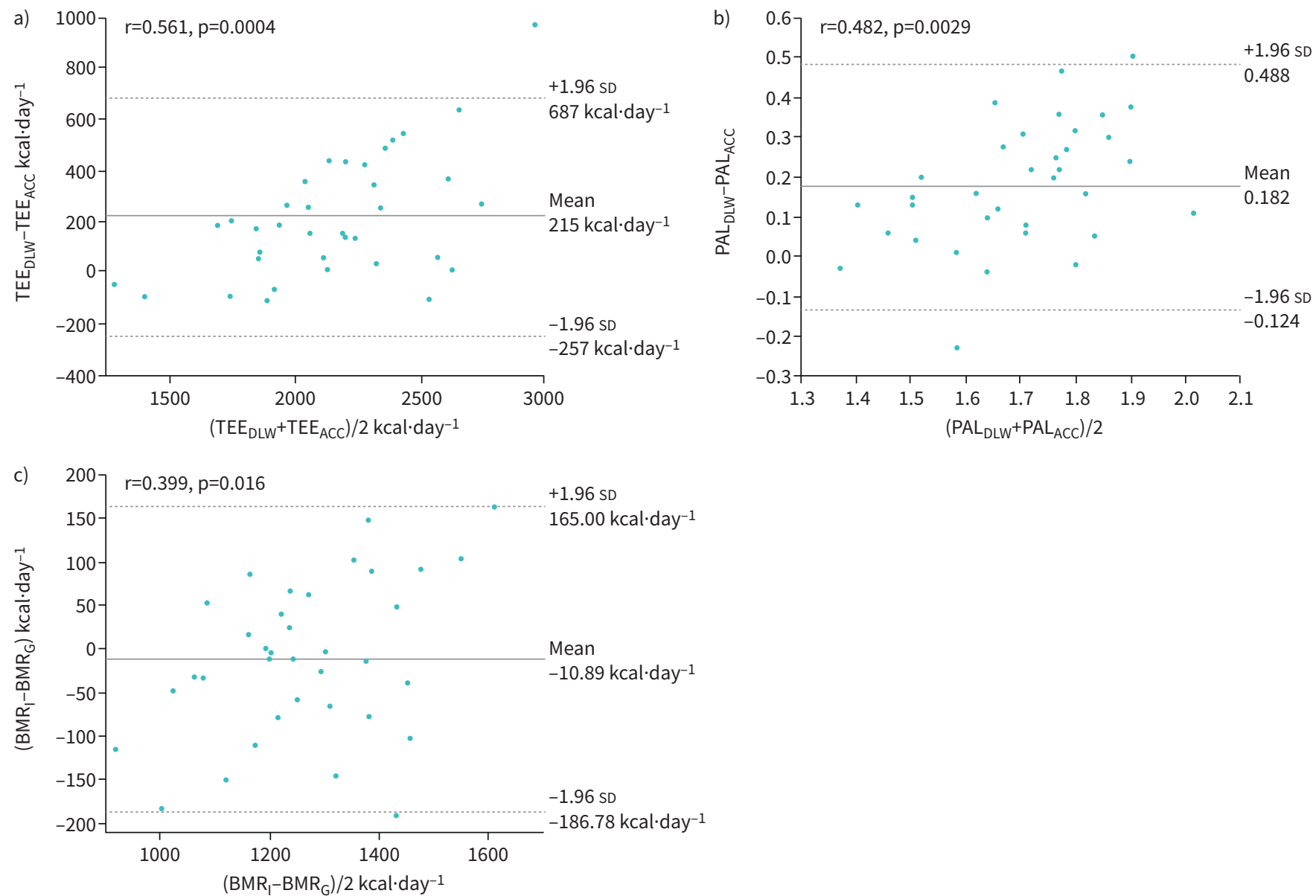

FIGURE 2 Bland-Altman plots for al total energy expenditure (TEE) and b) physical activity level (PAL), used to compare the values determined by the doubly labelled water (DLW) and accelerometer (ACC) methods, and c) basal metabolic rate (BMR), to compare the values obtained by indirect calorimetry $\left(B M R_{1}\right)$ and the Ganpule $\left(B M R_{G}\right)$ equation. Mean values are depicted by solid lines, while dotted lines show ranges within the $95 \%$ confidence interval. The $95 \%$ confidence interval for the difference in TEE was 133.5-296.6 kcal-day ${ }^{-1}$ ( $p<0.0001$ ) and that in PAL was $0.129-0.235$ $(p<0.0001)$ between the two methods. No difference in BMR $\left(95 \% \mathrm{Cl}-25.8-4.1 \mathrm{kcal}^{-}\right.$day ${ }^{-1}$, nonsignificant) was seen between measurements and the predicted values.

increased during certain activities in COPD patients as compared to healthy subjects. The difference between $\mathrm{AEE}_{\mathrm{DLW}}\left(784 \mathrm{kcal} \cdot \mathrm{day}^{-1}\right)$ and $\mathrm{AEE}_{\mathrm{ACC}}\left(580 \mathrm{kcal} \cdot \mathrm{day}^{-1}\right)$ nearly corresponded to that between $\mathrm{TEE}_{\mathrm{DLW}}\left(2273 \mathrm{kcal} \cdot \mathrm{day}^{-1}\right)$ and $\mathrm{TEE}_{\mathrm{ACC}}\left(2058 \mathrm{kcal} \cdot \mathrm{day}^{-1}\right)$ in the total population. Figure 1a suggests that $\sim 200-300 \mathrm{kcal} \cdot \mathrm{day}^{-1}$ should be added to the estimated energy expenditure by the accelerometer in COPD patients at GOLD 1 or 2 .

As compared to the DLW method, accelerometers can provide additional information, such as steps per day and sedentary, walking and daily activity times. Of interest is the observation that the associations of light and moderate daily activity times with $\mathrm{TEE}_{\mathrm{DLW}}$ and $\mathrm{PAL}_{\mathrm{DLW}}$ were greater than those observed for steps per day, sedentary time and light and moderate walking times. As the present results showed the best index was moderate daily activity time (3.0-6.0 METs), further analysis of daily activities is needed to clarify how best to maintain physical activity in COPD.

In 2005, PITTA et al. [26] reported that physical activity monitored by an accelerometer was significantly decreased in COPD patients versus healthy elderly subjects, in contrast to our findings. These differences may be partly attributable to the distinct study populations. Mean $\mathrm{FEV}_{1}$ was $43 \%$ in COPD patients and $111 \%$ in healthy subjects in the study by PIтTA et al., while values in our study were $62 \%$ and $95 \%$, respectively. In addition, all GOLD 0 patients were symptomatic, with most requiring bronchodilator treatment. Moreover, use of long-acting inhaled bronchodilator may have contributed to the differences in outcomes between the study by PIтTA et al. and the present investigation, as only salmeterol was available before 2005, while various kinds of long-acting muscarinic antagonists and $\beta_{2}$-agonists are now commonly available and in widespread use. In 2015, WASCHKI et al. [27] reported that PAL evaluated by an accelerometer decreased proportional to the extent of airflow limitation in GOLD grades $0-4$. This trend 


\section{TABLE 3 Relationships between energy expenditure/physical activity and clinical parameters}

\begin{tabular}{|c|c|c|c|c|}
\hline & \multicolumn{2}{|c|}{ TEE $_{\mathrm{DLW}}$} & \multicolumn{2}{|c|}{ PAL DLW } \\
\hline & $\mathbf{r}$ & p-value & $\mathbf{r}$ & p-value \\
\hline Age years & -0.361 & $<0.05$ & 0.132 & NS \\
\hline mMRC & 0.217 & NS & 0.276 & NS \\
\hline CAT & 0.282 & NS & 0.213 & NS \\
\hline BMI kg. $\mathrm{m}^{-2}$ & 0.623 & $<0.0001$ & 0.158 & NS \\
\hline Fat mass \% & 0.005 & NS & 0.092 & NS \\
\hline $\mathrm{FFMI} \mathrm{kg} \cdot \mathrm{m}^{-2}$ & 0.655 & $<0.0001$ & 0.226 & NS \\
\hline SMI $\mathrm{kg} \cdot \mathrm{m}^{-2}$ & 0.593 & $<0.001$ & 0.156 & NS \\
\hline Grip strength kg & 0.689 & $<0.0001$ & 0.538 & $<0.001$ \\
\hline$P_{\text {Emax }} \%$ & 0.255 & NS & 0.188 & NS \\
\hline$P_{\text {Imax }} \%$ & 0.020 & NS & 0.280 & NS \\
\hline Vital capacity \% & 0.359 & $<0.05$ & 0.301 & NS \\
\hline $\mathrm{FEV}_{1} \%$ & 0.313 & NS & 0.394 & $<0.05$ \\
\hline $\mathrm{FEV}_{1} / \mathrm{FVC} \%$ & 0.143 & NS & 0.286 & NS \\
\hline Residual volume \% & 0.165 & NS & 0.134 & NS \\
\hline$D_{\mathrm{Lco}} / V_{\mathrm{A}} \%$ & 0.387 & $<0.05$ & 0.258 & NS \\
\hline LAA $\%$ & -0.334 & $<0.05$ & -0.275 & NS \\
\hline 6MWD m & 0.355 & $<0.05$ & 0.575 & $<0.001$ \\
\hline$\Delta \mathrm{S}_{\mathrm{pO}_{2}} \%$ & 0.056 & NS & 0.142 & NS \\
\hline$\Delta \mathrm{HR}$ beats $\cdot \mathrm{min}^{-1}$ & 0.330 & $<0.05$ & 0.520 & $<0.01$ \\
\hline Dyspnoea & 0.048 & NS & 0.009 & NS \\
\hline Leg fatigue & -0.322 & $<0.05$ & -0.269 & NS \\
\hline
\end{tabular}

TEE: total energy expenditure; DLW: doubly labelled water; PAL mMRC: modified Medical Research Council dyspnoea scale; CAT: COPD Assessment Test; BMI: body mass index; FFMI: fat-free mass index; SMI: skeletal muscle mass index; $P_{\text {Emax }}$ : maximum expiratory pressure: $P_{\text {Imax }}$ : maximum inspiratory pressure; $F E V_{1}$ : forced expiratory volume in $1 \mathrm{~s}$; FVC: forced vital capacity; $D_{\mathrm{LCO}}$ : diffusing capacity of the lung for carbon monoxide; $V_{\mathrm{A}}$ : alveolar volume; LAA: low attenuation area; 6MWD: 6-min walk distance; $S_{\mathrm{pO}_{2}}$ : percutaneous oxygen saturation; HR: heart rate; NS: nonsignificant.
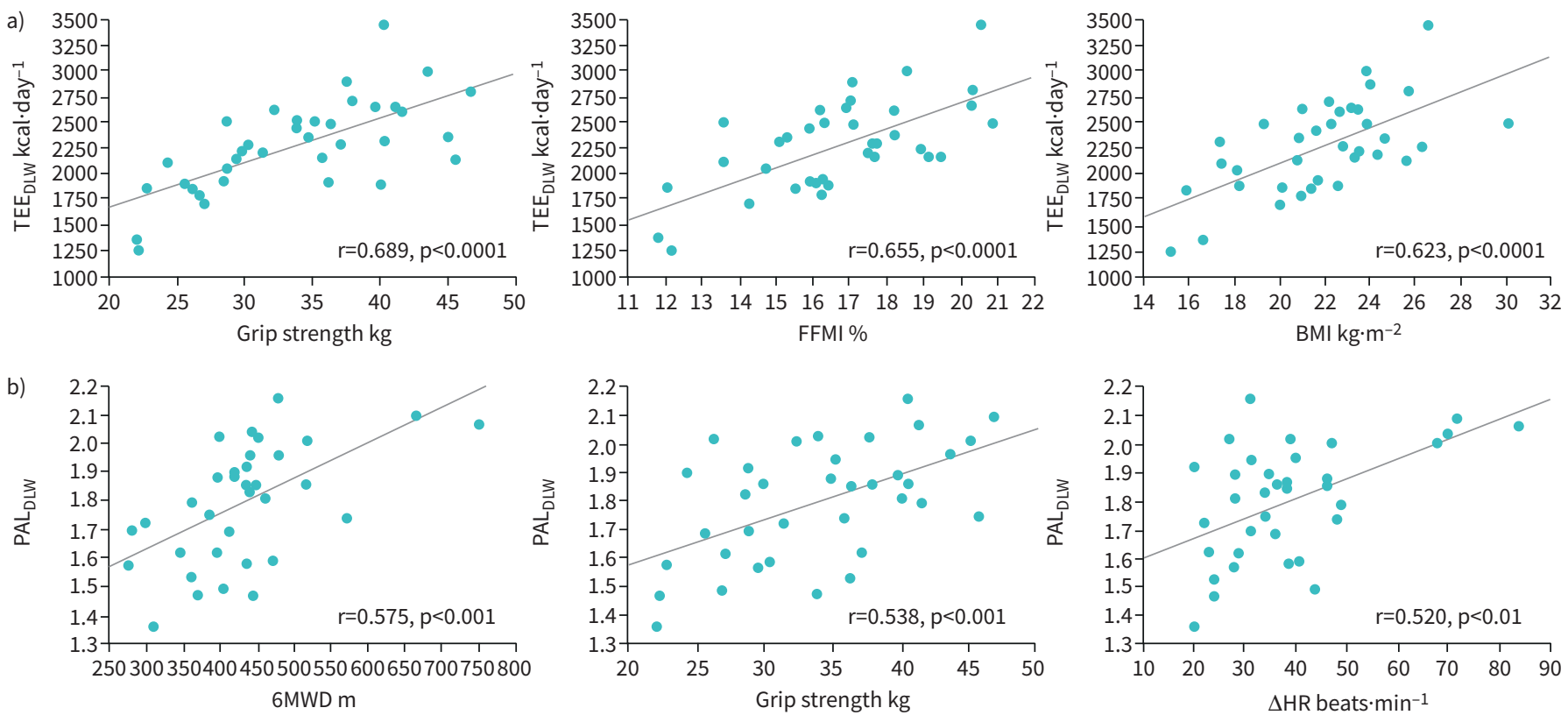

FIGURE 3 Correlations between a) total energy expenditure determined using the doubly labelled water method (TEE $E_{D L W}$ ) or b) physical activity level determined using TEE $E_{D L W}\left(P A L_{D L W}\right.$ ) and clinical parameters. There was a good correlation between the grip strength, fat-free mass index (FFMI) and body mass index (BMI) and the TEE $E_{D L W}$. 6-min walk distance (6MWD), grip strength, and the change in heart rate ( $\triangle \mathrm{HR}$ ) during the 6-min walk test were well correlated with the PAL $L_{D L W}$. 


\begin{tabular}{|c|c|c|c|c|}
\hline & \multicolumn{2}{|c|}{ TEE $_{\mathrm{DLW}}$} & \multicolumn{2}{|c|}{ PAL $_{\text {DLW }}$} \\
\hline & $\mathbf{r}$ & p-value & $\mathbf{r}$ & p-value \\
\hline Steps per day & 0.185 & NS & 0.377 & $<0.05$ \\
\hline Sedentary time min & 0.022 & NS & 0.088 & NS \\
\hline Light walking time min & 0.055 & NS & 0.191 & NS \\
\hline Moderate walking time min & 0.205 & NS & 0.362 & $<0.05$ \\
\hline Vigorous walking time min & 0.380 & $<0.05$ & 0.246 & NS \\
\hline Light daily activity time min & 0.385 & $<0.05$ & 0.465 & $<0.01$ \\
\hline Moderate daily activity time min & 0.551 & $<0.001$ & 0.471 & $<0.01$ \\
\hline 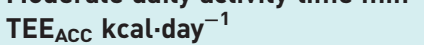 & 0.854 & $<0.0001$ & 0.554 & $<0.001$ \\
\hline PAL $_{A C C}$ & 0.531 & $<0.001$ & 0.642 & $<0.0001$ \\
\hline $\mathrm{AEE}_{\mathrm{ACC}} \mathrm{kcal} \cdot \mathrm{day}^{-1}$ & 0.722 & $<0.0001$ & 0.635 & $<0.0001$ \\
\hline
\end{tabular}

was consistent with our observations that PAL tended to decrease in GOLD 3 or 4 as compared to that observed in GOLD 1 or 2 . One of the most important findings in the study by WASCHKI et al. was that PAL was significantly decreased at 3 years after baseline measures in all groups classified by GOLD stage. Thus, inhibiting the progression of physical inactivity is important for every COPD patient, regardless of the degree of obstruction.

Analysis based on the DLW method demonstrated that TEE correlated modestly with $\% \mathrm{VC}, \% D_{\mathrm{LCO}} / \mathrm{V}_{\mathrm{A}}$ and LAA\% $(p<0.05)$, but even better with grip strength and FFMI $(p<0.0001)$. In addition, more significant correlations with $\mathrm{PAL}_{\mathrm{DLW}}$ were seen for grip strength $(\mathrm{p}<0.001), 6 \mathrm{MWD}(\mathrm{p}<0.001)$ and change in HR during 6MWT $(\mathrm{p}<0.01)$ as compared to $\% \mathrm{FEV}_{1}(\mathrm{p}<0.05)$. These observations imply that energy expenditure and physical activity in COPD patients were primarily determined by muscle strength in general and exercise capacity, while the contributions of pulmonary function were relatively small, based on $\mathrm{TEE}_{\mathrm{DLW}}$. These findings were consistent with the notion that $\mathrm{PAL}_{\mathrm{DLW}}$ correlated with changes in $\mathrm{HR}$,
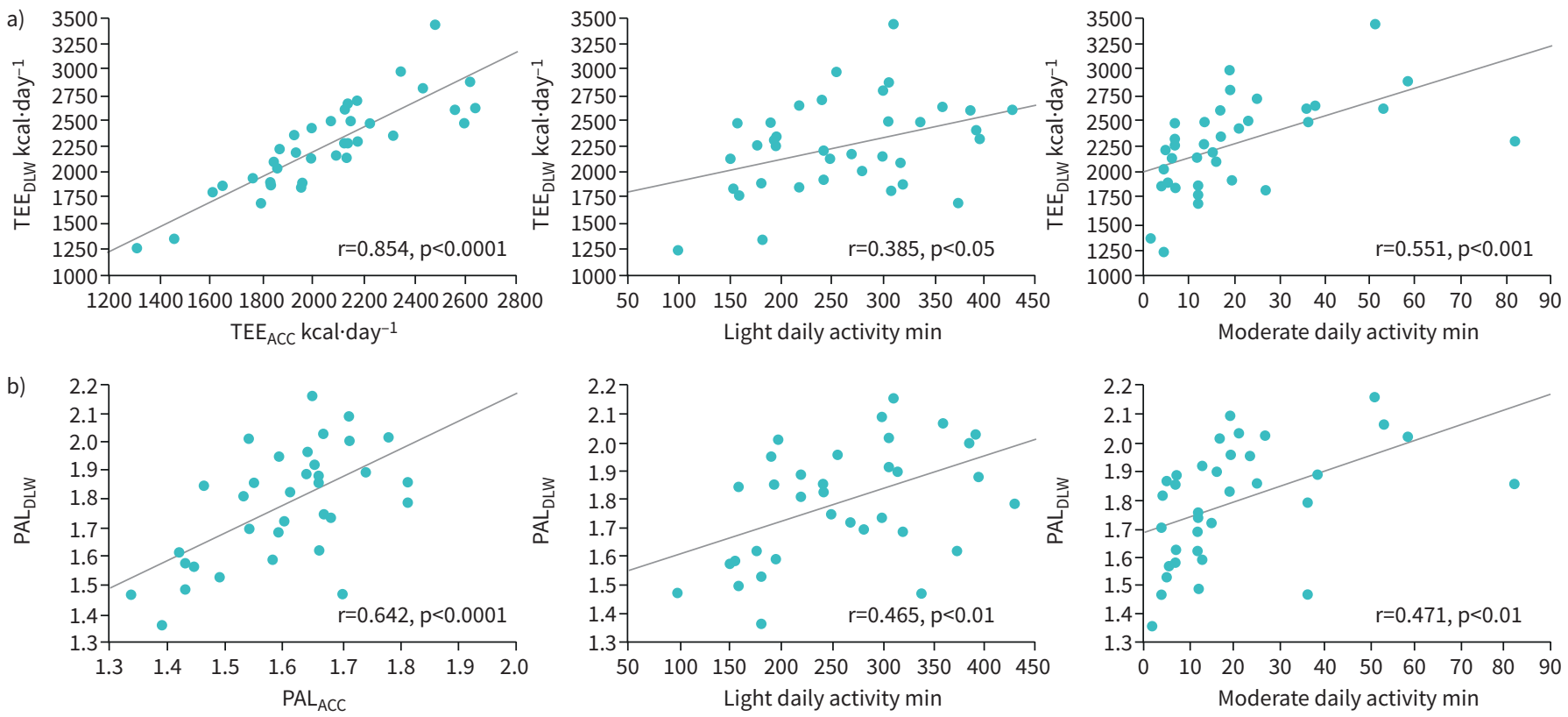

FIGURE 4 Correlations of a) total energy expenditure determined using the doubly labelled water method (TEE determined using $T E E_{D L W}\left(P A L_{D L W}\right)$ with the accelerometer (ACC) parameters. TEE $E_{D L W}$ was strongly correlated with $T E E_{A C C}(r=0.854, p<0.0001)$, while the association between $P A L_{D L W}$ and $P A L_{A C C}$ was relatively modest $(r=0.642, p<0.0001)$. Light (1.5-3.0 metabolic equivalents (METs)) and moderate (3.0-6.0 METs) daily activity times were correlated with both indices. 
but not with change in $S_{\mathrm{pO}_{2}}$ or dyspnoea during the 6MWT. This demonstrates that dyspnoea on exertion

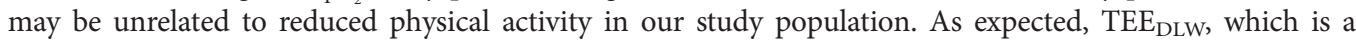
very important index for determining energy intake in COPD, was more significantly related to BMI, FFMI, SMI and grip strength than to the other factors.

Several limitations to this study need to be considered when interpreting the present findings. Due to the difficulties inherent in using the DLW method, the study population was relatively small. Furthermore, women were not included to avoid sex differences in TEE and PAL. In addition, the study population included only two patients with very severe COPD and excluded patients with diabetes mellitus who required medication.

In conclusion, TEE and PAL were preserved in patients with mild to moderate COPD, as well as those at risk of COPD. TEE and PAL values as estimated by the accelerometer were lower than those from the DLW method, but correlated with each other and showed differences related to activity energy expenditure. TEE and PAL can also be estimated by the accelerometer with clinical parameters including exercise capacity and muscle strength. These observations may promote better monitoring of the physical status in patients with mild to moderate COPD and could help prevent the development of future weight loss and poor prognosis.

Acknowledgements: We thank Azusa Sasaki (National Institutes of Biomedical Innovation, Health and Nutrition, Tokyo, Japan) and Hitoshi Miyazawa (Saitama Medical University, Saitama, Japan) for their skillful technical assistance.

Conflict of interest: H. Sato has nothing to disclose. H. Nakamura reports grants from the Japan Agency for Medical Research and Development (AMED) during the conduct of the study. Y. Nishida has nothing to disclose. T. Shirahata has nothing to disclose. S. Yogi has nothing to disclose. T. Akagami has nothing to disclose. M. Soma has nothing to disclose. K. Inoue has nothing to disclose. M. Niitsu has nothing to disclose. T. Mio has nothing to disclose. T. Miyashita has nothing to disclose. M. Nagata has nothing to disclose. S. Nakae has nothing to disclose. Y. Yamada has nothing to disclose. S. Tanaka reports grants from the Japan Agency for Medical Research and Development (AMED) during the conduct of the study. F. Katsukawa reports grants from the Japan Agency for Medical Research and Development (AMED) during the conduct of the study.

Support statement: This work was supported by the Japan Agency for Medical Research and Development (grant numbers JP17ek0210045 and JP20ek0210112). Funding information for this article has been deposited with the Crossref Funder Registry.

\section{References}

1 Global Initiative for Chronic Obstructive Lung Disease (GOLD). Global Strategy for the Diagnosis, Management, and Prevention of Chronic Obstructive Pulmonary Disease 2020 Report. https://goldcopd.org/wp-content/uploads/ 2019/11/GOLD-2020-REPORT-ver1.0wms.pdf

2 Celli BR, Cote CG, Marin JM, et al. The body-mass index, airflow obstruction, dyspnea, and exercise capacity index in chronic obstructive pulmonary disease. N Engl J Med 2004; 350: 1005-1012.

3 Waschki B, Kirsten A, Holz O, et al. Physical activity is the strongest predictor of all-cause mortality in patients with COPD: a prospective cohort study. Chest 2011; 140: 331-342.

4 Schols AM, Ferreira IM, Franssen FM, et al. Nutritional assessment and therapy in COPD: a European Respiratory Society statement. Eur Respir J 2014; 44: 1504-1520.

5 Garvey C, Bayles MP, Hamm LF, et al. Pulmonary rehabilitation exercise prescription in chronic obstructive pulmonary disease: review of selected guidelines. J Cardiopulm Rehabil Prev 2016; 36: 75-83.

6 Watz H, Pitta F, Rochester CL, et al. An official European Respiratory Society statement on physical activity in COPD. Eur Respir J 2014; 44: 1521-1537.

7 Mantoani LC, Rubio N, McKinstry B, et al. Interventions to modify physical activity in patients with COPD: a systematic review. Eur Respir J 2016; 48: 69-81.

8 Farooqi N, Carlsson M, Håglin L, et al. Energy expenditure in women and men with COPD. Clin Nutr ESPEN 2018; 28: 171-178.

9 Farooqi N, Slinde F, Håglin L, et al. Assessment of energy intake in women with chronic obstructive pulmonary disease: a doubly labeled water method study. J Nutr Health Aging 2015; 19: 518-524.

10 Donahoe M, Rogers RM, Wilson DO, et al. Oxygen consumption of the respiratory muscles in normal and in malnourished patients with chronic obstructive pulmonary disease. Am Rev Respir Dis 1989; 140: 385-391.

11 Hugli O, Schutz Y, Fitting JW. The daily energy expenditure in stable chronic obstructive pulmonary disease. Am J Respir Crit Care Med 1996; 153: 294-300.

12 Farooqi N, Slinde F, Carlsson M, et al. Predicting energy requirement with pedometer-determined physical-activity level in women with chronic obstructive pulmonary disease. Int J Chron Obstruct Pulmon Dis 2015; 10: 1129-1137.

13 Hayata A, Minakata Y, Matsunaga K, et al. Differences in physical activity according to mMRC grade in patients with COPD. Int J Chron Obstruct Pulmon Dis 2016; 11: 2203-2208.

14 Rabinovich RA, Louvaris Z, Raste Y, et al. Validity of physical activity monitors during daily life in patients with COPD. Eur Respir J 2013; 42: 1205-1215.

15 Kubota M, Kobayashi H, Quanjer PH, et al. Reference values for spirometry, including vital capacity, in Japanese adults calculated with the LMS method and compared with previous values. Respir Investig 2014; 52: 242-250.

16 ATS Committee on Proficiency Standards for Clinical Pulmonary Function Laboratories. ATS statement: guidelines for the six-minute walk test. Am J Respir Crit Care Med 2002; 166: 111-117. 
17 Tanabe N, Muro S, Sato S, et al. Fractal analysis of low attenuation clusters on computed tomography in chronic obstructive pulmonary disease. BMC Pulm Med 2018; 18: 144.

18 Morino K, Kondo K, Tanaka S, et al. Total energy expenditure is comparable between patients with and without diabetes mellitus: Clinical Evaluation of Energy Requirements in Patients with Diabetes Mellitus (CLEVER-DM) Study. BMJ Open Diabetes Res Care 2019; 7: e000648.

19 Weir JB. New methods for calculating metabolic rate with special reference to protein metabolism. J Physiol 1949; 109: 1-9.

20 Ganpule AA1, Tanaka S, Ishikawa-Takata K, et al. Interindividual variability in sleeping metabolic rate in Japanese subjects. Eur J Clin Nutr 2007; 61: 1256-1261.

21 Miyake R, Tanaka S, Ohkawara K, et al. Validity of predictive equations for basal metabolic rate in Japanese adults. J Nutr Sci Vitaminol 2011; 57: 224-232.

22 Ohkawara K, Oshima Y, Hikihara Y, et al. Real-time estimation of daily physical activity intensity by a triaxial accelerometer and a gravity-removal classification algorithm. Br J Nutr 2011; 105: 1681-1691.

23 Yamada Y, Hashii-Arishima Y, Yokoyama K, et al. Validity of a triaxial accelerometer and simplified physical activity record in older adults aged 64-96 years: a doubly labeled water study. Eur J Appl Physiol 2018; 118 2133-2146.

24 Hills AP, Mokhtar N, Byrne NM. Assessment of physical activity and energy expenditure: an overview of objective measures. Front Nutr 2014; 1: 5.

25 Doré MF, Laaban JP, Orvoën-Frija E, et al. Role of the thermic effect of food in malnutrition of patients with chronic obstructive pulmonary disease. Am J Respir Crit Care Med 1997; 155: 1535-1540.

26 Pitta F, Troosters T, Spruit MA, et al. Characteristics of physical activities in daily life in chronic obstructive pulmonary disease. Am J Respir Crit Care Med 2005; 171: 972-977.

27 Waschki B, Kirsten AM, Holz O, et al. Disease progression and changes in physical activity in patients with chronic obstructive pulmonary disease. Am J Respir Crit Care Med 2015; 192: 295-306. 